\section{JURNAL EKONOMI EFEKTIF}

ISSN : 2622 - 8882, E-ISSN : 2622-9935

Jurnal Ekonomi Efektif, Vol. 2, No. 4, Juli 2020

@ Prodi Manajemen Fakultas Ekonomi Universitas

Pamulang

\title{
PENGARUH KUALITAS PELAYANAN TERHADAP KEPUASAN KONSUMEN PADA INDOMARET CABANG PONDOK RANJI
}

\author{
Retno Wulansari \\ Universitas Pamulang, Tangerang Selatan, Banten, Indonesia \\ *dosen00568@unpam.ac.id
}

\begin{abstract}
ABSTRAK
Penelitian ini bertujuan untuk mengetahui pengaruh kualitas pelayanan terhadap kepuasan konsumen pada Indomaret Cabang Pondok Ranji. Metode yang digunakan adalah explanatory research dengan sampel sebanyak 87 responden. Teknik analisis menggunakan analisis statistik dengan pengujian regresi, korelasi, determinasi dan uji hipotesis. Hasil penelitian ini variabel kualitas pelayanan diperoleh nilai rata-rata skor sebesar 3,402 dengan kriteria baik. Variabel kepuasan konsumen diperoleh nilai rata-rata skor sebesar 3,801 dengan kriteria baik. Kualitas pelayanan berpengaruh positif dan signifikan terhadap kepuasan konsumen dengan nilai persamaan regresi $Y=10,482+0,809 X$, dan nilai koefisien korelasi 0,760 atau memiliki tingkat hubungan yang kuat dengan nilai determinasi 57,8\%. Uji hipotesis diperoleh signifikansi $0,000<0,05$.
\end{abstract}

\section{Kata Kunci: Kualitas Pelayanan, Kepuasan Konsumen.}

\section{ABSTRACT}

This study aims to determine the effect of service quality on customer satisfaction at Indomaret Pondok Ranji Branch. The method used is explanatory research with a sample of 87 respondents. The analysis technique uses statistical analysis with regression testing, correlation, determination and hypothesis testing. The results of this study the variable service quality obtained an average score of 3.402 with good criteria. The consumer satisfaction variable obtained an average score of 3.801 with good criteria. Service quality has a positive and significant effect on customer satisfaction with the regression equation value $Y=10.482$ $+0.809 X$, and the correlation coefficient value of 0.760 or has a strong level of relationship with a determination value of $57.8 \%$. Hypothesis testing obtained a significance of 0.000 $<0.05$.

Keywords: Service Quality, Customer Satisfaction. 


\section{PENDAHULUAN}

\section{A. Latar Belakang Masalah}

Dalam menghadapi persaingan yang ketat di era globalisasi ini, setiap perusahaan harus mampu bersaing untuk memenangkan persaingan. Orientasi dunia pemasaran mengalami perubahan dari profit oriented kepada satisfied oriented. Setiap perusahaan harus memperhatikan dan mempertimbangkan kepuasan konsumen. Masalah yang sering dihadapi oleh perusahaan adalah bahwa perusahaan belum tentu mampu memberikan kepuasan maksimal yang benar benar diharapkan oleh konsumen atau pelanggan. (Amanah 2010).

Untuk menghadapi kompleksitas dan intensitas tantangan yang semakin berat, pimpinan perusahaan atau organisasi dituntut berfikir kreatif untuk menemukan berbagai terobosan strategi yang mampu menciptakan sinergi yang memberikan kontribusi optimal bagi pencapaian tujuan organisasi. Untuk itulah perusahaan-perusahaan dituntut untuk dapat menerapkan suatu kebijakan-kebijakan yang strategis menyangkut pelayanan guna mengantisipasi adanya iklim persaingan yang semakin kompetitif. Salah satu unsur terpenting didalam suatu organisasi adalah keunggulan pelayanan yang dimilikinya. Keunggulan pelayanan didalam suatu organisasi atau perusahaan, setidaknya dapat menjadi keberhasilan suatu perusahaan dalam menghadapi segala tantangan dan ancaman yang akan menghambat laju perkembangan perusahaan dimasa yang akan datang.

Mengingat betapa pentingnya peran kualitas pelayanan bagi kehidupan suatu organisasi atau perusahaan untuk berupaya meningkatkan potensi yang dimiliki, agar kualitas dan kuantitas pelayanan tersebut dapat bersaing atau setidaknya mampu mengimbangi laju persaingan di dunia usaha. Pelayanan pelanggan ini sangat penting artinya bagi kehidupan suatu perusahaan, karena tanpa pelanggan, maka tidak akan terjadi transaksi jual beli diantara keduanya. Untuk itu kegiatan pelayanan perusahaan haruslah berorientasi pada kepuasan pelanggan.

Kualitas pelayanan karyawan terhadap kepuasan konsumen dapat memberikan kontribusi kepada perusahaan dalam meningkatkan pendapatan jangka panjangnya adalah pada sejauh mana kemampuan perusahaan atau organisasi melayani atau memberi pelayanan secara maksimal kepada para pelanggannya secara sistematis dan terprogram yang tidak melanggar nilai- nilai etika dalam sebuah bisnis.

Pada industri atau bisnis yang berorientasi pada pelanggan, maka tidak dapat dihindari bahwa kualitas pelayanan menjadi satu-satunya faktor penentu dari eksistensi perusahaan atau industri tersebut dalam terlibat di industri atau bisnis yang penuh dengan persaingan, karena jika kualitas pelayanan tidak diperhatikan, maka konsekuensinya pelanggan akan berpindah kepada industri atau bisnis lain yang sejenis yang lebih memberikan pelayanan yang memuaskan bagi konsumennya.

Kualitas pelayanan adalah mutu dari pelayanan yang diberikan kepada pelanggan baik pelangan internal maupun eksternal. (Ernawati \& Sriwidodo dalam Anwar 2012:84).

Kepuasan konsumen adalah tingkat perasaan konsumen setelah membandingkan antara apa yang diterima dan harapannya. (Suryoko 2013:65) Dalam melihat dimensi apa saja yang mempengaruhi kualitas sebuah pelayanan dalam bisnis, khususnya pada sektor jasa terhadap kepuasan konsumen, dimana semua merupakan beberapa dimensi dari kualitas pelayanan sebuah bisnis atau industri dilaksanakan. Dimana pada akhirnya dimensi-dimensi tersebut diatas akan secara signifikan mempengaruhi daya beli masyarakat atau konsumen kepada industri atau bisnis yang kita jalankan.

Berdasarkan paparan diatas, penulis tertarik untuk melakukan penelitian mendalam mengenai aspek pelayanan yang menjadi selling value pengaruhnya terhadap kepuasan 
konsumen. Kita percaya bahwa kepuasan konsumen akan banyak memberikan dampak positif bagi kelangsungan hidup sebuah usaha. Dari latar belakang diatas tersebut, maka judul penelitian yang ingin diangkat oleh penulis adalah "Pengaruh Kualitas Pelayanan Terhadap Kepuasan Konsumen Pada Indomaret Cabang Pondok Ranji”

\section{B. Rumusan Masalah}

1. Bagaimana kualitas pelayanan pada Indomaret Cabang Pondok Ranji ?.

2. Bagaimana kepuasan konsumen pada Indomaret Cabang Pondok Ranji ?.

3. Adakah pengaruh antara kualitas pelayanan terhadap kepuasan konsumen pada Indomaret Cabang Pondok Ranji ?.

\section{Tujuan Penelitian}

1. Untuk mengetahui kondisi kualitas pelayanan pada Indomaret Cabang Pondok Ranji.

2. Untuk mengetahui kondisi kepuasan konsumen pada Indomaret Cabang Pondok Ranji.

3. Untuk mengetahui pengaruh antara kualitas pelayanan terhadap kepuasan konsumen pada Indomaret Cabang Pondok Ranji.

\section{TINJAUAN PUSTAKA}

\section{Kualitas pelayanan}

Kualitas pelayanan adalah mutu dari pelayanan yang diberikan kepada pelanggan baik pelangan internal maupun eksternal. (Ernawati \& sriwidodo dalam anwar 2012:84).

\section{Kepuasan Konsumen}

Kepuasan konsumen adalah tingkat perasaan konsumen setelah membandingkan antara apa yang diterima dan harapannya. (Suryoko, 2013:65)

\section{METODE PENELITIAN}

\section{Populasi}

Populasi dalam penelitian ini berjumlah 87 responden konsumen Indomaret Cabang Pondok Ranji

2. Sampel

Teknik pengambilan sampling dalam penelitian ini adalah sampel jenuh, dimana semua anggota populasi dijadikan sebagai sampel. Dengan demikian sampel dalam penelitian ini sampel yang digunakan berjumlah 87 responden.

\section{Jenis Penelitian}

Jenis penelitian yang dipakai adalah asosiatif, dimana tujuannya adalah untuk mengetahui atau mencari keterhubungan antara variabel independen terhadap variabel dependennya

\section{Metode Analisis Data}

Dalam menganalisis data digunakan uji validitas, uji reliabilitas, analisis regresi linier sederhana, analisis koefisien korelasi, analisis koefisien determinasi dan pengujian hipotesis.

\section{HASIL PENELITIAN}

\section{Analisis Deskriptif}

Pada pengujian ini digunakan untuk mengetahui skor minimum dan maksimum skor tertinggi, ratting score dan standar deviasi dari masing-masing variabel. Adapun hasilnya 
sebagai berikut:

Tabel 1. Hasil Analisis Descriptive Statistics

\section{Descriptive Statistics}

\begin{tabular}{l|r|r|r|r|r} 
& N & Minimum & Maximum & Mean & \multicolumn{1}{c}{ Std. Deviation } \\
\hline Kualitas pelayanan (X) & 87 & 29 & 44 & 34.02 & 3.879 \\
\hline Kepuasan konsumen (Y) & 87 & 29 & 49 & 38.01 & 4.127 \\
\hline Valid N (listwise) & 87 & & & & \\
\hline
\end{tabular}

Kualitas pelayanan diperoleh varians minimum sebesar 29 dan varians maximum 44 dengan ratting score sebesar 3,402 dengan standar deviasi 3,879. Skor ini termasuk pada rentang sakala 3,40-4,19 dengan kriteria baik atau setuju.

Kepuasan konsumen diperoleh varians minimum sebesar 29 dan varians maximum 49 dengan ratting score sebesar 3,801 dengan standar deviasi 4,127. Skor ini termasuk pada rentang sakala 3,40 - 4,19 dengan kriteria baik atau setuju.

\section{Analisis Verifikatif.}

Pada analisis ini dimaksudkan untuk mengetahui pengaruh variabel independen terhadap variabel dependen. Adapun hasil pengujian sebagai berikut:

\section{a. Analisis Regresi Linier Sederhana}

Uji regresi ini dimaksudkan untuk mengetahui perubahan variabel dependen jika variabel independen mengalami perubahan. Adapun hasil pengujiannya sebagai berikut:

Tabel 2. Hasil Pengujian Regresi Linier Sederhana

\begin{tabular}{lr|r|r|r|r} 
& \multicolumn{2}{c}{ Coefficients $^{\mathbf{a}}$} \\
& \multicolumn{2}{c}{$\begin{array}{l}\text { Unstandardized } \\
\text { Coefficients }\end{array}$} & $\begin{array}{c}\text { Standardized } \\
\text { Coefficients }\end{array}$ & & \\
Model & \multicolumn{1}{c}{ B } & Std. Error & Beta & \multicolumn{1}{c}{ t } & \multicolumn{1}{c}{ Sig. } \\
\hline 1 (Constant) & 10.482 & 2.566 & & 4.085 & .000 \\
\hline Kualitas pelayanan (X) & .809 & .075 & .760 & 10.796 & .000 \\
\hline
\end{tabular}

Berdasarkan hasil pengujian pada tabel di atas, diperoleh persamaan regresi $\mathrm{Y}=$ $10,482+0,809 X$. Dari persamaan tersebut dijelaskan sebagai berikut:

1) Konstanta sebesar 10,482 diartikan jika kualitas pelayanan tidak ada, maka telah terdapat nilai kepuasan konsumen sebesar 10,482 point.

2) Koefisien regresi kualitas pelayanan sebesar 0,809 , angka ini positif artinya setiap ada peningkatan kualitas pelayanan sebesar 0,809 point maka kepuasan konsumen juga akan mengalami peningkatan sebesar 0,809 point.

\section{b. Analisis Koefisien Korelasi}

Analisis koefisien korelasi dimaksudkan untuk mengetahui tingkat kekuatan hubungan dari variabel independen terhadap variabel dependen. Adapun hasil pengujian sebagai berikut:

Tabel 3. Hasil Pengujian Koefisien Korelasi Kualitas pelayanan Terhadap Kepuasan konsumen.

\begin{tabular}{llrr} 
& \multicolumn{1}{c}{ Correlations $^{\mathbf{b}}$} & $\begin{array}{c}\text { Kualitas } \\
\text { pelayanan (X1) }\end{array}$ & \multicolumn{1}{c}{$\begin{array}{c}\text { Kepuasan } \\
\text { konsumen (Y) }\end{array}$} \\
\hline Kualitas pelayanan (X) & Pearson Correlation & 1 & $.760^{* *}$ \\
\cline { 2 - 4 } & Sig. (2-tailed) & .000 \\
\hline Kepuasan konsumen (Y) & Pearson Correlation & $.760^{* *}$ & 1 \\
\cline { 2 - 4 } & Sig. (2-tailed) & .000 & \\
\hline
\end{tabular}


Berdasarkan hasil pengujian diperoleh nilai korelasi sebesar 0,760 artinya kualitas pelayanan memiliki hubungan yang kuat terhadap kepuasan konsumen.

\section{c. Analisis Koefisien Determinasi}

Analisis koefisien determinasi dimaksudkan untuk mengetahui besarnya persentase pengaruh dari variabel independen terhadap variabel dependen. Adapun hasil pengujian sebagai berikut:

Tabel 4. Hasil Pengujian Koefisien Determinasi Kualitas pelayanan Terhadap Kepuasan konsumen.

\begin{tabular}{|c|c|c|c|c|}
\hline \multicolumn{5}{|c|}{ Model Summary } \\
\hline Model & $\mathrm{R}$ & R Square & $\begin{array}{l}\text { Adjusted R } \\
\text { Square }\end{array}$ & $\begin{array}{l}\text { Std. Error of the } \\
\text { Estimate }\end{array}$ \\
\hline 1 & $.760^{a}$ & .578 & .573 & 2.696 \\
\hline
\end{tabular}

Berdasarkan hasil pengujian diperoleh nilai determinasi sebesar 0,578 artinya kualitas pelayanan memiliki kontribusi pengaruh sebesar $57,8 \%$ terhadap kepuasan konsumen, sedangkan sisanya sebesar $42,1 \%$ dipengaruhi oleh faktor lain yang tidak dilakukan penelitian.

\section{d. Uji Hipotesis}

Pengujian hipotesis dengan uji $\mathrm{t}$ digunakan untuk mengetahui hipotesis mana yang diterima.

Rumusan hipotesis: Terdapat pengaruh yang signifikan antara kualitas pelayanan terhadap kepuasan konsumen.

Tabel 5. Hasil Uji Hipotesis Kualitas pelayanan Terhadap Kepuasan konsumen.

\begin{tabular}{|c|c|c|c|c|c|}
\hline \multirow[b]{2}{*}{ Model } & $\begin{array}{r}\text { Co } \\
\text { Unst } \\
\text { Co }\end{array}$ & $\begin{array}{l}\text { ficients }^{a} \\
\text { idardized } \\
\text { ficients }\end{array}$ & \multirow{2}{*}{$\begin{array}{c}\text { Standardized } \\
\text { Coefficients } \\
\text { Beta }\end{array}$} & \multirow[b]{2}{*}{$\mathrm{t}$} & \multirow[b]{2}{*}{ Sig. } \\
\hline & B & Std. Error & & & \\
\hline 1 (Constant) & 10.482 & 2.566 & & 4.085 & .000 \\
\hline Kualitas pelayanan (X) & .809 & .075 & .760 & 10.796 & .000 \\
\hline
\end{tabular}

Berdasarkan hasil pengujian pada tabel di atas, diperoleh nilai t hitung $>\mathrm{t}$ tabel atau $(10,796>1,988)$, dengan demikian hipotesis yang diajukan bahwa terdapat pengaruh yang signifikan atara kualitas pelayanan terhadap kepuasan konsumen diterima.

\section{Pembahasan Hasil Penelitian}

\section{Kondisi Jawaban Responden Variabel Kualitas pelayanan}

Berdasarkan jawaban responden, variabel kualitas pelayanan diperoleh ratting score sebesar 3,402 berada di rentang skala 3,40 - 4,19 dengan kriteria baik atau setuju.

\section{Kondisi Jawaban Responden Variabel Kepuasan konsumen}

Berdasarkan jawaban responden, variabel kepuasan konsumen diperoleh ratting score sebesar 3,801 berada di rentang skala 3,40-4,19 dengan kriteria baik atau setuju.

\section{Pengaruh Kualitas pelayanan Terhadap Kepuasan konsumen}

Kualitas pelayanan berpengaruh signifikan terhadap kepuasan konsumen dengan persamaan regresi $\mathrm{Y}=10,482+0,809 \mathrm{X}$, nilai korelasi sebesar 0,760 atau memiliki hubungan yang kuat dengan kontribusi pengaruh sebesar 57,8\%. Pengujian hipotesis 
diperoleh nilai $t$ hitung $>\mathrm{t}$ tabel atau $(10,796>1,988)$. Dengan demikian hipotesis yang diajukan bahwa terdapat berpengaruh signifikan antara kualitas pelayanan terhadap kepuasan konsumen diterima.

\section{KESIMPULAN DAN SARAN}

1. Kesimpulan

a. Variabel kualitas pelayanan diperoleh ratting score sebesar 3,402 berada di rentang skala 3,40 - 4,19 dengan kriteria baik atau setuju.

b. Variabel kepuasan konsumen diperoleh ratting score sebesar 3,801 berada di rentang skala 3,40-4,19 dengan kriteria baik atau setuju.

c. Kualitas pelayanan berpengaruh signifikan terhadap kepuasan konsumen dengan persamaan regresi $\mathrm{Y}=10,482+0,809 \mathrm{X}$, nilai korelasi sebesar 0,760 atau kuat dan kontribusi pengaruh sebesar 57,8\% sedangkan sisanya sebesar $42,1 \%$ dipengaruhi faktor lain. Uji hipotesis diperoleh nilai $t$ hitung $>t$ tabel atau $(10,796>1,988)$.

\section{Saran}

Dari hasil yang telah peneliti dapatkan maka pada bab ini peneliti ingin memberikan saran-saran dari hasil yang peneliti dapatkan, adapun saran-saran yang ingin diberikan adalah:

a. Diharapkan agar Indomaret Cabang Pndok Ranji dapat lebih meningkatan dalam memberikan pelayanan yang cepat dan memuaskan.

b. Diharapkan Indomaret Cabang Pondok Ranji dapat lebih memperlakukan konsumen dengan penuh perhatian untuk meningkatan kualitas pelayanan terhadap kepuasan konsumen.

c. Diharapkan Indomaret Cabang Pondok Ranji memberikan perlakuan yang lebih sopan dan baik terhadap konsumen sehingga konsumen merasa puas dengan pelayanan yang diberikan

\section{DAFTAR PUSTAKA}

Abdullah, M (2014) Manajemen dan Evaluasi Kepuasan konsumen, Yogyakarta: Penerbit Aswaja Pressindo.

Algifari. (2015). “Analisis Regresi untuk Bisnis dan Ekonomi”. Yogyakarta: BPFE.

Arikunto, Suharsimi (2014). "Prosedur Penelitian Suatu Pendekatan Praktek". Jakarta: Rineka Cipta.

Bashu Swastha dan T. Handoko (2015) Manajemen Pemasaran Moderen, Yogyakarta: BPFE. Bilson Simamora (2016) Panduan Riset Prilaku Konsumen, Jakarta: PT. Gramedia Pustaka. Fandy Tjiptono (2017), Serivce Quality and Satisfiation. Jakarta: Edisi tiga. Andi.

Freddy Rangkuti (2016) Strategi Promosi Yang Kreatif, Edisi Pertama, Cetakan Pertama Jakarta: Gramedia Pustaka Utama.

Imam Ghozali (2017). “Aplikasi Analisis Multivariate Dengan Program SPSS”. Edisi Kelima. Semarang: Badan Penerbit Undip.

Istijanto (2014) “Riset Sumber Daya Manusia”. Jakarta: PT. Gramedia Pustaka

Ilham, D. (2014). Implementasi Nilai-Nilai Keagamaan pada Mata Pelajaran Umum dalam Upaya Peningkatan Akhlak Peserta Didik di MAN Malili Kabupaten Luwu Timur (Doctoral dissertation, STAIN/IAIN Palopo).

Ilham, D. (2019). Implementing Local Wisdom Values in Bride and Groom Course at KUA Bara SubDistrict, Palopo City. Jurnal Konsepsi, 8(1), 1-9. 
Ilham, D. (2019). Menggagas Pendidikan Nilai dalam Sistem Pendidikan Nasional. Didaktika: Jurnal Kependidikan, 8(3), 109-122.

Jasmani, J., \& Sunarsi, D. (2020). The Influence of Product Mix, Promotion Mix and Brand Image on Consumer Purchasing Decisions of Sari Roti Products in South Tangerang. PINISI Discretion Review, 1(1), 165-174.

Jasmani, J., Maduningtias, L., \& Irmal, I. (2019). Pelatihan Dan Penguasaan Digital Marketing Dalam Meningkatkan Pendapatan Para Remaja Di Lingkungan Benda Timur IV. Jurnal Pengabdian Dharma Laksana, 2(1), 65-68.

Kharis, Ismu Fadli (2011). "Studi Mengenai Impulse Buying dalam Penjualan Online”. Semarang : Skripsi Universitas Diponegoro

Kotler dan Amstrong (2017), Prinsip-prinsip Pemasaran. Edisi Kedua Belas”. Jilid Satu. Jakarta: Erlangga.

Lupiyoadi (2016) Manajemen Pemasaran Jasa, Edisi 4, Jakarta: Salemba Empat.

Philip Kotler (2017) Manajemen Pemasaran, Edisi Keempat Belas, Jakarta: PT. Indeks.

Phipil Kotler dan Kevin Keller (2017) Manajemen Pemasaran, Edisi Kedua Belas, Jilid Satu, Jakarta: Erlangga.

Rao, Purba, (2012). "Measuring Consumer Perceptions Through Factor Analysis", The Asian.

Santoso, Singgih (2015). "Menguasai Statistik Multivariat”. Jakarta: PT Elex Media Komputindo.

Sudjana (2014) “Metode Statistika”, Bandung: Tarsido.

Sugiyono (2017), "Metode Penelitian Administrasi : dilengkapi dengan Metode $R \& D$ ”. Bandung: Alfabeta.

Suhartanto (2014). “Metode Riset Pemasaran”. Bandung: Alfabeta

Sunarsi, D., \& Baharuddin, A. (2019). The Effect of Service Quality and Price Accuracy on Consumer Confidence and Implications for Sales Increase. PINISI Discretion Review, 3(2), 101-110.

T Triyadi, U Ahidin, J Jasmani - Jurnal Manajemen, Bisnis dan Organisasi (JUMBO), 2019. Pengaruh Promosi Dan Kualitas Pelayanan Terhadap Kepuasan Pelanggan Pada PT. Surya Karya Prima Di Jakarta. 